\title{
Effects of Surface Grinding Conditions on the Reciprocating Friction and Wear Behavior of Silicon Nitride
}

\author{
P. J. Blau*, R. L. Martin, and E. S. Zanoria \\ Oak Ridge National Laboratory \\ P. O. Box 2008 \\ Oak Ridge, TN 37831-6063 USA \\ *phone: (423) 574-5377; fax: (423) 574-6918 \\ *email address: "blaupj@ornl.gov"
}

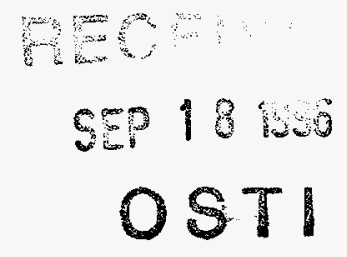

\section{Abstract}

The relationship between two significantly different surface grinding conditions and the reciprocating ball-on-flat friction and wear behavior of a high-quality, structural silicon nitride material (GS-44) was investigated. The slider materials were silicon nitride NBD 200 and $440 \mathrm{C}$ stainless steel. Two machining conditions were selected based on extensive machining and flexural strength test data obtained under the auspices of an intemational, interlaboratory grinding study. The condition categorized as "low strength" grinding used a coarse 80 grit wheel and produced low flexure strength due to machining-induced flaws in the surface. The other condition, regarded as "high strength grinding," utilized a 320 grit wheel and produced a flexural strength nearly $70 \%$ greater. Grinding wheel surface speeds were 35 and $47 \mathrm{~m} / \mathrm{s}$. Reciprocating sliding tests were conducted following the procedure described in a newly-published ASTM standard (G133) for linearly-reciprocating wear. Tests were performed in directions both parallel and perpendicular to the grinding marks (lay) using a $25 \mathrm{~N}$ load, $5 \mathrm{~Hz}$ reciprocating frequency, $10 \mathrm{~mm}$ stroke length, and $100 \mathrm{~m}$ of sliding at room temperature. The effects of sliding direction relative to the lay were more pronounced for stainless steel than for silicon nitride sliders. The wear of stainless steel was less than the wear of the silicon nitride slider materials because of the formation of transfer particles which covered the sharp edges of the silicon nitride grinding grooves and reduced abrasive contact. The wear of the GS -44 material was much greater for the silicon nitride sliders than for the stainless steel sliders. The causes for the effects of surface-grinding severity and sliding direction on friction and wear of GS-44 and its counterface materials are explained.

* Research sponsored by the U.S. Department of Energy, Assistant Secretary for Energy Efficiency and Renewable Energy, Office of Transportation Technologies, Propulsion Systems Materials Program, under contract DE-ACO5-960R22464 with Lockheed Martin Energy Research Corp.

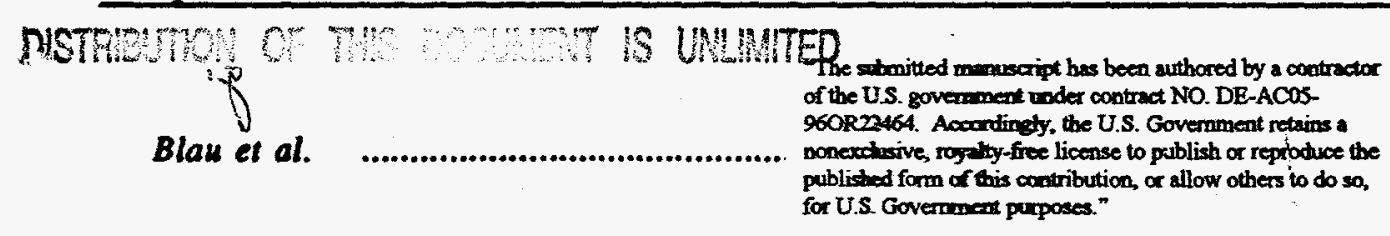




\section{DISCLAMMER}

Portions of this document may be illegible in electronic image products. Images are produced from the best available original document. 


\section{Introduction}

The properties and uses of advanced structural ceramics, like silicon carbide, alumina, transformation-toughened zirconia, SiAION, and silicon nitride have witnessed considerable improvement in the last fifteen years. For example, alumina and silicon carbide water pump seals and silicon nitride rolling element bearings are now commercially-available products. While additional property improvements are still desirable, an important factor in widening the introduction of these materials is their cost. Grinding and final finishing, which are primarily controlled abrasive wear, are important elements of that cost.

Structural ceramics used for tribological applications have special requirements for finished surface quality. In such cases, it becomes important to establish the relationship between the degree to which material can be expeditiously removed by machining and the resultant durability and frictional behavior of the finished surfaces.

The current paper reports the results of a study of the effects of grinding method on the reciprocating friction and wear of a high-quality silicon nitride material. The variables were method of grinding, slider material, and direction of sliding contact. In this work, we used GS-44 silicon nitride for the ground surface and selected two different sets of grinding conditions. The grinding parameters, representing abusive and mild conditions, were selected based on a comprehensive multi-national study of the relationship between machining parameters and the flexure strength of GS-441. That study determined that GS -44 would fail in flexure primarily from surface-related flaws rather than volume flaws making it particularly suitable for studying the effects of machining on mechanical properties.

\section{Materials}

Flat slabs of GS-44 were obtained from AlliedSignal, Ceramic Components Division, Torrance, California. Materials used for the sliders were (1) silicon nitride type NBD 200 (Norton Advanced Ceramics, East Granby, Connecticut), and (2) stainless steel type 440C (Hoover Group, Cumming, Georgia). Their typical properties are given in Table 1.

\section{Machining Method}

The stock GS-44 material for each condition was a rectangular billet with its length parallel to the grinding direction. The billets were machined with two sets of conditions using a Harig 
CNC II creep-feed grinder. The two conditions differed primarily in the abrasive grit size of the 12.7- $\mathrm{mm}$ wide, resin-bonded diamond wheel. The condition categorized as "low strength" used a coarse 80 grit (typical particle diameter $=177 \mu \mathrm{m}$ ) wheel with an outer diameter of $152.4 \mathrm{~mm}$. The other, regarded as "high strength," utilized a $203.2 \mathrm{~mm}$ diameter wheel containing finer 320 grit (typical particle diameter $=44 \mu \mathrm{m}$ ) abrasives. The two surface speeds of the wheels were $35 \mathrm{~m} / \mathrm{s}$ and $47 \mathrm{~m} / \mathrm{s}$, respectively. These speeds are typical of machining practice. Machining for both conditions used a table speed of $200 \mathrm{~mm} / \mathrm{min}$, a down feed of $0.018 \mathrm{~mm}$ and a cross-feed of 1.8 $\mathrm{mm}$ with a water-based grinding fluid. After grinding, billets were each cut into five square coupons with dimensions of $25.4 \mathrm{~mm} \times 25.4 \mathrm{~mm} \times 5.7 \mathrm{~mm}$ The background on the Intemational Energy Agency (IEA) project is described elsewhere. ${ }^{1}$ Data for the current materials, obtained from K. Breder ${ }^{2}$, involved at least 20 test specimens per grinding condition. The specimens were oriented such that the surface lay was transverse to the long axis of the bend specimens. This orientation results in the greatest sensitivity to grinding conditions. The average four-point flexural strength of the low strength and high strength machining conditions were 571 (std dev. 22) MPa and 963 (std. dev 31) MPa, respectively.

Surface roughness measurements of the GS-44 specimens were obtained using a Talysurf 10 (Taylor Hobson Ltd., Leicester, England) profilometer with a tip radius of $2.5 \mu \mathrm{m}$. In summary, a total of 6 sampling segments constituted the profilometry data for each grinding condition. The arithmetic average roughness $R_{a}$ and root-mean-square roughness $R_{q}$ were measured, and the results are listed in Table 2.

\section{Friction and Wear Testing Method}

Reciprocating friction and wear testing conditions were those specified in Procedure A of ASTM Standard G-133-95 "Standard Test Method for Linearly Reciprocating Ball-on-Flat Sliding Wear ${ }^{m 3}$. These conditions are as follows:

$$
\begin{aligned}
& \text { normal force }=25 \mathrm{~N} \\
& \text { stroke length }=10.0 \mathrm{~mm} \\
& \text { reciprocating rate }=5 \mathrm{cycles} / \mathrm{s} \\
& \text { test duration }=1000 \mathrm{~s}(100 \text { meters }) \\
& \text { atmosphere }=\text { room temperature air } \\
& \text { relative humidity during testing }=40-60 \% \mathrm{RH}
\end{aligned}
$$


The actual \% RH throughout the test series remained in the range $45-60 \%$ RH except for one experiment in which the humidity was $66 \%$ RH. The data for the latter were consistent with the other data and were included in the results. Tests were conducted on a Plint and Partners TE-77 machine which was calibrated using a load cell for normal force and a pulley and weight system for tangential (friction) force. Friction data were obtained from a chart recorder trace of the rectified output of the root-mean-square friction force.

Wear of the sliders was calculated based on the dimensions of the scars determined from photomicrographs of the tips of the slider balls after post-test cleaning with acetone. The wear volume $\left(V_{p}\right)$ for a flat ball wear scar of effective diameter $D$ is found from the same relationship given in ASTM standard G-99, Appendix, X1.1.1:

$$
V_{p}=(\pi h / 6)\left[3 D^{2} / 4+h^{2}\right]
$$

where, $\mathrm{h}=$ height of material removed, $\mathrm{mm}$. Assuming a spherical wear volume, the height of material removed can be calculated from $D$ as follows:

$$
h=R-\left[R^{2}-\left(D^{2} / 4\right)\right]^{1 / 2}
$$

where, $\mathbf{R}=$ original ball radius, $\mathrm{mm}$

The wear rate (WR), expressed in $\mathrm{mm}^{3} / \mathrm{N}$-cycle, is obtained from:

$$
W R=\left(V_{p} / P N\right)
$$

where $\mathrm{P}$ is the normal force and $\mathrm{N}$ is the number of sliding cycles.

In the case of flat, round scars, the diameter was used to calculate the wear rate. For oval scars, the average of the length and width of the scar was used to calculate wear rate. Since the oval scars contained more undulations and were not completely flat, there is more uncertainty in the wear rates calculated for oval scars. This uncertainty is estimated to be of the order of $\pm 25 \%$ in wear rate.

The wear rates of the flat specimens were obtained by a calibrated Rodenstock laser profiling instrument. The cross sectional area of the wear track was obtained at three places on 
each track and the average multiplied by track length to obtain wear volume. Wear rate was calculated using Eqn. (3).

\section{Results}

The frictional behavior for the various conditions and material combinations examined in this study varied considerably both in terms of the magnitude of the steady-state friction coefficients and in the nature of the friction force as a function of time. The average, steady-state friction coefficients for the two slider materials, the two ground conditions, and the two sliding directions are summarized in Fig. 1(a) and (b). Bars represent the data obtained in two tests. Low-strength grinding refers to the surfaces prepared with the 80 grit wheel and high-strength grinding refers to specimens prepared with the 320 grit wheel. The term longitudinal refers to sliding parallel to the lay of the surface, and transverse refers to sliding across the lay. There was much less influence of sliding direction for the silicon nitride couples than for the stainless steel/silicon nitride combinations, and the friction coefficients for the silicon nitride sliders were higher.

The wear rates of the slider materials are portrayed in Fig. 2(a) and (b). As with the sliding friction, we found that the effects of surface lay were more pronounced for stainless steel sliders than for the silicon nitride sliders. It is worthwhile noting that the stainless steel wore less than the silicon nitride, particularly when sliding was performed in the transverse direction. Table 3 provides information on the shape of the wear scars, their appearance, and the wear rates of the ball materials. A number of trends emerge from the data and observations:

a. The wear scars on the stainless steel balls were always round.

b. The wear scars on the silicon nitride balls were always oval with the shorter dimension in the sliding direction.

c. The stainless steel slid along the lay had coarser abrasion marks than when slid transversely to the lay.

d. There were accumulations of fine debris particles, some relatively adherent, on the silicon nitride slider tips but not on the steel slider tips.

e. The wear rates of the steel tips were always less than those for the silicon nitride tips, particularly for the transverse sliding direction.

There was also a trend for increasing ball wear rate with increasing friction coefficient (Fig. 3). This trend was clearer for the steel balls than for the silicon nitride balls. 
Low-magnification photomicrographs of the sliding wear tracks of both stainless steel and silicon nitride sliders are shown in Fig. 4. It is clear that the wear of the GS-44 was minimal against steel but significant against NBD 200. Wear tracks of the stainless steel reciprocated parallel to the lay appeared only as a brownish "shadow" on the specimens, with no discernible grooves having been produced. Wear data for the GS-44 specimens are summarized in Table 4. There was too little wear of the GS -44 against steel to obtain a measurement, so the wear can be considered negligible. On the other hand, there was a very large amount of GS-44 wear against the NBD 200 sliders. So deep were the grooves that the mechanical stylus instrument we normally use to measure wear had insufficient range to make the measurement and we used a non-contact laser system instead. Using the non-contact system offered the additional advantage of being able to map the topography of the wear scars. A cross-section of one of the deep wear grooves in the silicon nitride is shown in Fig. 5. Scanning electron microscopy of the deep grooves produced by the silicon nitride balls revealed that the original surface grinding marks had been completely obliterated (Fig. 6). Therefore, the effects of surface roughness were expected to be only temporary during the initial run-in process.

Optical microscopy of the steel wear tracks showed significant evidence for third body creation and asperity truncation (Fig. 7). Stylus profiles of the machined surface and the stainless steel wear surface convincingly illustrate how the original asperities were wom away and the how some of the valleys between them were filled-in by third bodies (Fig. 8 (a) and (b)). The shaving and debris layer forming processes were most evident for GS-44 specimens in which stainless steel sliders moved transversely to the lay (see Fig. 6). Knoop microindentations were made on the narrow, abraded ridges of silicon nitride at $50 \mathrm{~g}(59.1 \mathrm{mN})$ load, and the average microindentation hardness was found to be $19.59 \mathrm{GPa}$ (std dev. $3.7 \mathrm{GPa}$ ), a value similar to that expected for silicon nitride. Nearly all attempts to place indentations in the granular debris material accumulated in the grooves failed because it microfractured too easily. The few readable Knoop impressions we managed to obtain in the debris layer produced an average microindentation hardness of approximately $7.7 \mathrm{GPa}$. The debris, composed of compacts of very fine, submicrometer particles, supported the load momentarily, but developed fissures from shear tractions (see Fig. 9).

The effects of sliding orientation on the variation of the friction force was most clear for $440 \mathrm{C}$ sliders. When they were slid transversely to the lay, the friction was relatively steady, but when they were slid longitudinally, the friction force fluctuated more, but remained lower. Representative friction traces for $440 \mathrm{C}$ sliders are shown in Fig. 10. 


\section{Discussion}

The reasons for the observed differences in friction and wear behavior among the two slider materials and grinding conditions can be summarized in terms of four dominant influences: (1) the shaving action of silicon nitride grinding grooves against the stainless steel, particularly in the transverse sliding direction, (2) debris trapping to reduce the friction coefficient during transverse sliding, (3) the formation of third-body layers, and (4) the severe wear of silicon nitride under self-mated conditions. These effects were documented by wear profile measurements, optical microscopy, and electron microscopy.

The effects of the initial surface finish on GS-44 were minimal for the silicon nitride sliders because they very quickly wore through the initial surface finish. As Table 4 indicates, the average wear rates for the GS-44 were only very slightly higher for the high strength condition in corresponding sliding orientations. One could interpret this small difference as being due to the higher grinding-induced residual stress in the low strength specimens, which helped to reduce wear. Work to characterize the residual stress states of the two grinding conditions continues in our laboratory.

In addition to evidence from SEM images, the rapid wear-in of silicon nitride sliders is supported by the preliminary fluctuations in friction which eventually lessened at steady state. The minor effects of sliding direction on friction and wear for the silicon nitride sliders confirms the fact that initial roughness contributed little to the long term behavior and that subsurface residual stresses had perhaps a minor effect at best. Under less severe sliding conditions (e.g., lubricated conditions or lower applied normal force) the effects of initial surface finish would be expected to persist longer 4,5 , but under the testing conditions of the present work, we did not observe such effects.

Wear of the GS-44 by NBD 200 in either high- or low-strength grinding conditions constituted a process of microfracture to generate very fine debris particles which subsequently agglomerated into easily removed debris layers. The features associated with microfracture and debris accumulation appeared similar to those observed at the centers of silicon nitride fretting contacts reported by Vizintin, et al. ${ }^{6}$. They used the same size slider ball but a higher load (88N), shorter stroke length $(5-50 \mu \mathrm{m})$, and higher oscillating frequency $(210 \mathrm{~Hz})$. In particular, the tests which those investigators conducted for 360 minutes at an amplitude of $50 \mu \mathrm{m}$ (effective sliding distance $454 \mathrm{~m}$ ) were most similar in wear scar appearance to our GS-44 specimens. This 
suggests that reciprocating sliding wear mechanisms for self-mated silicon nitride operate similarly over a wide range of sliding amplitudes and contact pressures.

The loose debris at the ends of the NBD 200 wear tracks appeared to the naked eye as a fine white powder and did not display the gray-green color of the specimen surface. Collected on a glass slide and viewed through the optical microscope, debris consisted of tiny colorless microgranular agglomerates and equiaxed fine particles, some of which were semi-transparent. It might be tempting at first to assume that the fine wear particles were silicon dioxide, the composition of the nanometer-thick natural layer which forms on silicon nitride surface exposed to air, however, the wear rate of GS- 44 by NBD 200 was so high that subsurface fracture must also have occurred to produce the high rate of material removal we obtained. Previous experiments with the ORNL friction microprobe ${ }^{7}$ showed that particle layers can form, fracture, and re-heal upon further sliding. Layer fracture and rehealing may have caused the momentary, periodic frictional fluctuations we observed in friction force/time traces.

The fact that the NBD 200 ball wear scars were oval and exhibited an undulated, polished appearance (see Fig. 11) suggests an abrasive wearing action by debris particles trapped at the sides of the contact as they slowly worked their way out. Since the ball tips were not flat, as confirmed by the conformal shapes of the wear grooves in the flat specimens, and thus, wear rates calculated for the silicon nitride balls are somewhat higher than actual rates because our calculation approximates the volume removed as a hemispherical cap.

In the case of stainless steel sliders, the abrasive markings on the ball tips were finer for runs in the transverse direction because material was shaved off by the fine edges of the ridges between grinding grooves. In the longitudinal direction, the slider traveled parallel to the machining grooves which cut like long, continuous knife-edges into the wear surface, leaving deeper and more prominent abrasion markings (see Fig. 12). Loose wear particles of the stainless steel were collected and appeared through the optical microscope as fine brownish or coppercolored shards, not displaying the clumping shown by the silicon nitride fines. This might be expected if the ability of the particles to hold a static electric surface charge was a factor in maintaining the state of debris agglomeration.

In light of the above, there emerges a consistent picture of the reciprocating, unlubricated friction and wear of ground silicon nitride against stainless steel and silicon nitride counterfaces. The combination having the least tribosystem wear and lowest friction coefficients was the $440 \mathrm{C}$ stainless steel sliding against GS- 44 in the low-strength condition and in the transverse direction. 
Running-in occurred quickly to produce a smooth flat spot by a shaving action, and this quickly lowered the nominal contact pressure. Stainless steel ball debris captured within the grinding grooves also helped reduce fluctuations in the friction force. Sharp asperities on the GS-44 were broken off soon after the onset of sliding and those which remained were quickly submerged in a layer of third bodies further reducing the abrasiveness of the original surface.

The most severe wear and the highest friction coefficients occurred for the NBD 200 sliders in the longitudinal direction on GS-44 in the high-strength ground condition. It is long established that similar materials are in general less tribologically compatible. When sliding wear occurs under these circumstances, the wear particles can form an abrasive layer in the interface to further accelerate material removal. The polished, undulated surfaces of the NBD 200 slider tips confirm this hypothesis. Furthermore, any surface-breaking median cracks produced normal to the grinding lay in a brittle material are more favorably oriented for tensile failure when sliding tractions are parallel to the lay. The slightly higher wear rates of the GS-44 in contact with NBD 200 in the longitudinal direction suggests could be a consequence of that effect.

\section{Summary}

Sliding friction and wear experiments were performed on ground GS-44 silicon nitride using silicon nitride (NBD 200) and stainless steel (AISI 440C) balls as sliders. Two grinding conditions on GS-44, one which produced high flexure strength and one which produced much lower strength, were compared. Sliding was performed both parallel and transverse to the lay of the surfaces. ASTM Standard G-133, Procedure A, sliding conditions were used. Because of rapid run-in and debris trapping, the rubbing couple which produced the lowest wear rates and the lowest friction coefficients was stainless steel $440 \mathrm{C}$ sliding transverse to the lay on the lower strength GS-44 specimen. Wear of the GS- 44 was negligible against $440 \mathrm{C}$ and the steel was shaved off the slider producing fine, powdery oxide debris. The most severe wear rates occurred for silicon nitride sliding on silicon nitride, irrespective of sliding direction and grinding condition. Wear occurred by microfracture and formation of brittle patches of micro-granular debris. For silicon nitride sliders, slightly less wear of GS-44 occurred for the low-strength ground condition suggesting, but still to be substantiated, that it may be the subsurface residual stresses and not the initial surface finish which ultimately governs the wear rate. For the stainless steel sliders, material removal was effected by shaving (micro-machining) action when sliding was transverse-to-the-lay, and abrasive grooving when sliding occurred in the direction parallel to the lay. Type $440 \mathrm{C}$ stainless steel against GS- 44 is a better choice than silicon nitride against GS-44 if there is a need 
to slide them together under unlubricated conditions, and given the choice, orienting the machining marks transverse to the sliding direction would be most beneficial.

\section{Acknowledgments}

This work was conducted at Oak Ridge National Laboratory as part of the Cost-Effective Ceramic Machining effort sponsored by the U.S. Department of Energy, Assistant Secretary for Energy Efficiency and Renewable Energy, Office of Transportation Technologies, Propulsion Systems Materials Program, under contract DE-AC05-960R22464 with Lockheed Martin Energy Research Corp. This project also supported the author's participation in the development of ASTM Standard G-133. 


\section{Table 1.}

\section{Materials Used in This Study}

\begin{tabular}{|c|c|c|c|}
\hline Property & $\begin{array}{c}\text { GS-44 } \\
\text { Silicon Nitride } \\
\text { (Note 1) } \\
\end{array}$ & $\begin{array}{c}\text { Type 440C } \\
\text { Stainless Steel } \\
\text { (Note 2) } \\
\end{array}$ & $\begin{array}{c}\text { NBD } 200 \\
\text { Silicon Nitride } \\
\text { (Note 3) } \\
\end{array}$ \\
\hline Elastic modulus (GPa) & 310. & 200. & 320. \\
\hline Poisson's ratio (approx.) & 0.26 & 0.28 & 0.26 \\
\hline Surface finish & $\begin{array}{l}\text { root-mean-square } \\
\text { roughness: } \\
0.53 \mu \mathrm{m} \text { (low } \\
\text { strength ground } \\
\text { condition); } 0.38 \\
\mu \mathrm{m} \text { (high strength } \\
\text { ground condition) }\end{array}$ & $\begin{array}{l}\text { AFBMA Grade } 10 \\
\text { finish }\end{array}$ & $\begin{array}{c}\text { AFBMA Grade } 5 \\
\text { finish }\end{array}$ \\
\hline Hardness & $\mathrm{HV}_{10 \mathrm{~kg}}=15.5$ & $\mathrm{BHN}=480$ & $\mathrm{HV}_{10 \mathrm{~kg}}=16.6$ \\
\hline Strength $(\mathrm{MPa})$ & $\begin{array}{l}\text { 1204. typ. } \\
\text { (flexural) }\end{array}$ & 1900.0 (yield) & $\begin{array}{l}800.0 \text { typ. } \\
\text { (flexural) }\end{array}$ \\
\hline $\begin{array}{l}\text { Fracture toughness } \\
\left(\mathrm{MPa}^{\left.-\mathrm{m}^{1 / 2}\right)}\right.\end{array}$ & 8.6 & - & 4.1 \\
\hline
\end{tabular}

Notes:

1. Data from Allied Signal Ceramic Components, Torrence, Califomia, 1994.

2. "Selecting Stainless Steels", Carpenter Technology, Reading, Pennsylvania, 1992.

3. Dala from manufacturer, Norton Advanced Ceramics, Worcester, Massachusetts.

Table 2.

Surface Finish Data

\begin{tabular}{|l|c|c|}
\hline & Transverse to the Lay & Parallel to the Lay \\
\hline \hline Low strength condition & $R_{a}=0.53 \mu \mathrm{m}, R_{q}=0.67 \mu \mathrm{m}$ & $R_{a}=0.16 \mu \mathrm{m}, R_{q}=0.20 \mu \mathrm{m}$ \\
\hline High strength condition & $R_{a}=0.38 \mu \mathrm{m}, R_{q}=0.48 \mu \mathrm{m}$ & $R_{a}=0.13 \mu \mathrm{m}, R_{q}=0.17 \mu \mathrm{m}$ \\
\hline
\end{tabular}


Table 3.

Summary of Data for the Worn Slider Tips (average of two tests per condition)

\begin{tabular}{|c|c|c|c|c|}
\hline & \multicolumn{2}{|c|}{ 440C Stainless Steel } & \multicolumn{2}{|c|}{ NBD $200 \mathrm{Si}_{3} \mathrm{~N}_{4}$} \\
\hline & Longitudinal & Transverse & Longitudinal & Transverse \\
\hline $\begin{array}{l}\text { LOW STRENGTH } \\
\text { Wear scar shape }\end{array}$ & round & round & oval & oval \\
\hline $\begin{array}{l}\text { Wear scar surface } \\
\text { features }\end{array}$ & coarse abrasion & fine abrasion & $\begin{array}{c}\text { smooth, wide } \\
\text { grooves }\end{array}$ & $\begin{array}{c}\text { smooth, wide } \\
\text { grooves }\end{array}$ \\
\hline $\begin{array}{l}\text { Wear rate } \\
\left(\mathrm{mm}^{3} / \mathrm{N} \text {-cycle }\right)\end{array}$ & $2.22 \times 10^{-5}$ & $1.33 \times 10^{-5}$ & $2.71 \times 10^{-5}$ & $2.48 \times 10^{-5}$ \\
\hline $\begin{array}{l}\text { HIGH STRENGTH } \\
\text { Wear scar shape }\end{array}$ & round & round & oval & oval \\
\hline $\begin{array}{l}\text { Wear scar surface } \\
\text { features }\end{array}$ & coarse abrasion & fine abrasion & $\begin{array}{l}\text { adherent debris } \\
\text { covered scar }\end{array}$ & $\begin{array}{c}\text { smooth, wide } \\
\text { grooves }\end{array}$ \\
\hline $\begin{array}{l}\text { Wear rate } \\
\left(\mathrm{mm}^{3} / \mathrm{N} \text {-cycle }\right)\end{array}$ & $2.39 \times 10^{-5}$ & $2.02 \times 10^{-5}$ & $3.34 \times 10^{-5}$ & $2.66 \times 10^{-5}$ \\
\hline
\end{tabular}


Table 4.

Wear Features and Data for GS-44 Specimens (average of two tests per condition)

\begin{tabular}{|c|c|c|c|c|}
\hline & \multicolumn{2}{|c|}{ 440C Stainless Steel } & \multicolumn{2}{|c|}{ NBD $200 \mathrm{Si}_{3} \mathrm{~N}_{4}$} \\
\hline & Longitudinal & Transverse & Longitudinal & Transverse \\
\hline $\begin{array}{l}\text { LOW STRENGTH } \\
\text { Wear scar features }\end{array}$ & $\begin{array}{l}\text { slight brown } \\
\text { discoloration; } \\
\text { little wear }\end{array}$ & $\begin{array}{l}\text { transferred } \\
\text { material in the } \\
\text { grinding } \\
\text { grooves }\end{array}$ & $\begin{array}{c}\text { micro-fractured } \\
\text { surface with } \\
\text { patches of fine } \\
\text { debris particles }\end{array}$ & $\begin{array}{l}\text { micro-fractured } \\
\text { surface with } \\
\text { patches of fine } \\
\text { debris particles }\end{array}$ \\
\hline $\begin{array}{l}\text { Wear rate } \\
\left(\mathrm{mm}^{3} / \mathrm{N} \text {-cycle }\right)\end{array}$ & $\mathrm{nm}^{*}$ & $\mathrm{~nm}^{*}$ & $1.41 \times 10^{-4}$ & $1.08 \times 10^{-4}$ \\
\hline $\begin{array}{l}\text { HIGH STRENGTH } \\
\text { Wear scar appearance }\end{array}$ & $\begin{array}{l}\text { slight brown } \\
\text { discoloration; } \\
\text { little wear }\end{array}$ & $\begin{array}{l}\text { transferred } \\
\text { material in the } \\
\text { grinding } \\
\text { grooves }\end{array}$ & $\begin{array}{c}\text { micro-fractured } \\
\text { surface with } \\
\text { patches of fine } \\
\text { debris particles }\end{array}$ & $\begin{array}{l}\text { micro-fractured } \\
\text { surface with } \\
\text { patches of fine } \\
\text { debris paricles }\end{array}$ \\
\hline $\begin{array}{l}\text { Wear rate } \\
\left(\mathrm{mm}^{3} / \mathrm{N} \text {-cycle }\right)\end{array}$ & $\mathrm{nm}^{*}$ & $\mathrm{~nm}^{*}$ & $1.70 \times 10^{-4}$ & $1.24 \times 10^{-4}$ \\
\hline
\end{tabular}

* $\mathrm{nm}=$ no measurable amount of wear, primarily transfer from the slider. 


\section{Eiqure captions.}

Figure 1. The average, steady-state friction coefficients for the two slider materials, the two ground conditions, and the two sliding directions are summarized. (a) stainless steel sliders, and (b) silicon nitride sliders.

Figure 2. Wear rates of the slider materials: (a) $440 \mathrm{C}$ stainless steel, (b) NBD 200.

Figure 3. Relationship between friction coefficients and ball wear rates on GS-44 specimens.

Figure 4. Low magnification (15x originally) optical photomicrographs of the sliding wear tracks of both stainless steel and silicon nitride sliders.

Figure 5. Laser-measured profile showing a cross section of a wear groove in the silicon nitride (high strength specimen, sliding transverse to the lay, vertically-hatched area $=44,710 \mu \mathrm{m}^{2}$ ).

Figure 6. The high wear rate of the GS-44 slid against NBD 200 silicon nitride obliterated the grinding grooves, as shown in this scanning electron micrograph of a wear track edge.

Figure 7. Optical micrograph of the transverse wear track from $440 \mathrm{C}$ stainless steel showing significant evidence for third body deposits ("D") and ridge abrasion ("A").

Figure 8. Stylus profiles of the machined surface adjacent to the wear track (a) and along the center of the stainless steel wear surface (b) showing how the original asperities were worn away and the how the valleys between them were partly filled-in by third bodies.

Figure 9. Debris compacts lay adjacent to smoother tops of abraded machining ridges but had little mechanical strength. Note the fine crack in the deposit. (SEM)

Figure 10. Typical friction force fluctuations for tests of $440 \mathrm{C}$ sliding on GS-44 (low strength): (a) longitudinal direction, (b) transverse direction.

Figure 11. Wear scar on a silicon nitride ball slid on GS-44 (high strength) transverse to the lay.

Figure 12. Photomicrographs of $440 \mathrm{C}$ stainless steel ball tips slid under (a) transverse and (b) longitudinal orientations (low-strength ground condition). 


\section{References}

1 V. J. Tennery (1991) "Cooperative International Program on Mechanical Strength Measurements of Ceramics," Proc. of the Ann. Automotive Technology Development Contractors Coordination Meeting, Society of Automotive Engineers, Pub. No. P.243, Warrendale, PA, pp. 221-225.

2 K. Breder (1995), Oak Ridge National Laboratory, personal communication.

3 ASTM Standard G-133-95 (1996) "Standard Test Method for Linearly Reciprocating Ball-onFlat Sliding Wear", Annual Book of Standards, Vol. 03.02 (in press).

4 P. J. Blau (1996) Eriction Science and Technology, Chapter 7, Marcel Dekker, Inc., New York, pp. 251-284.

5 P. J. Blau (1992) "Effects of surface preparation on the friction and wear behaviour of silicon nitride/silicon carbide sliding pairs," J. of Mater. Sci., Vol. 27, pp. $4632-4740$.

6 J. Vizintin, M. Kalin, S. Novak, G. Drazic, L. K. Ives, and M. B. Peterson (1996) "Effect of slip amplitude on the fretting wear of silicon nitride against silicon nitride," Wear, Vol. 192, pp. 11-20.

7 P. J. Blau (1993) "Friction microprobe investigation of particle layer effects on sliding friction," Wear, Vol. 162-164, pp. 102-109. 


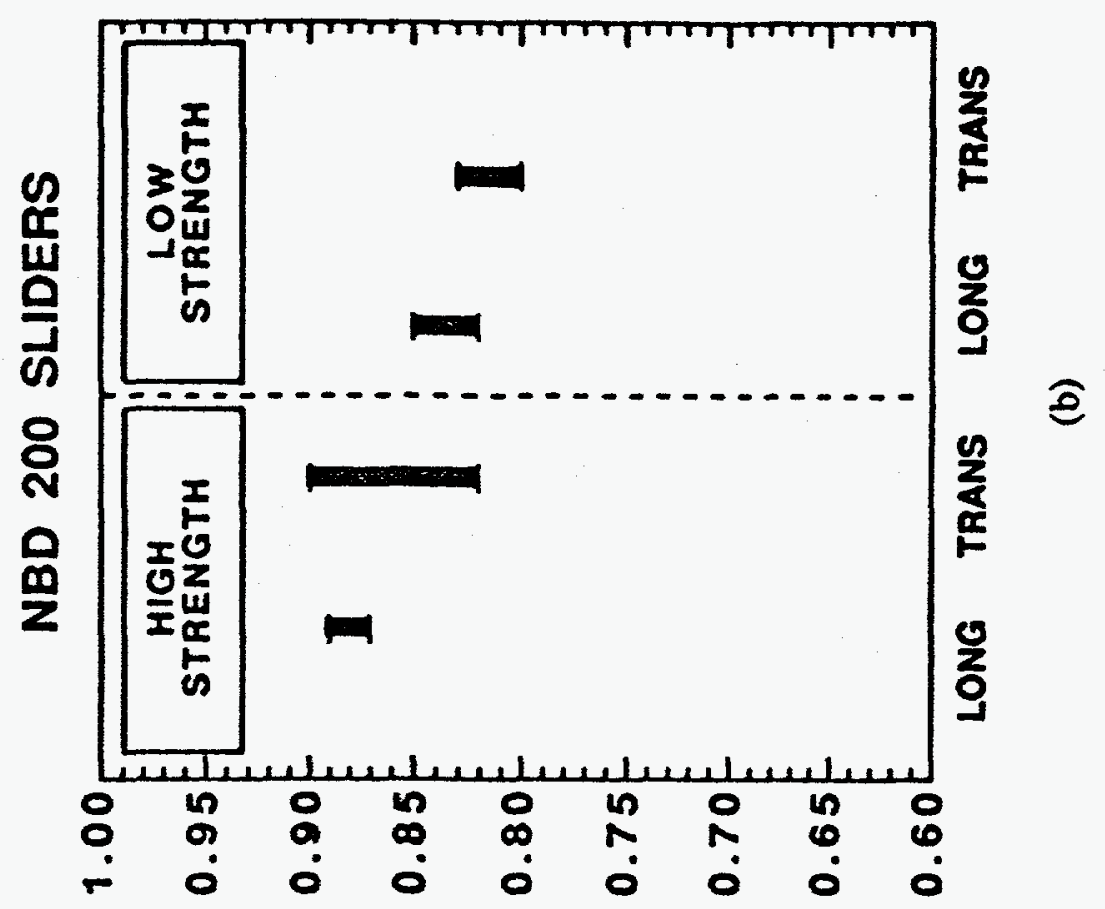

(әIE) Rpeo|s) $\pi$

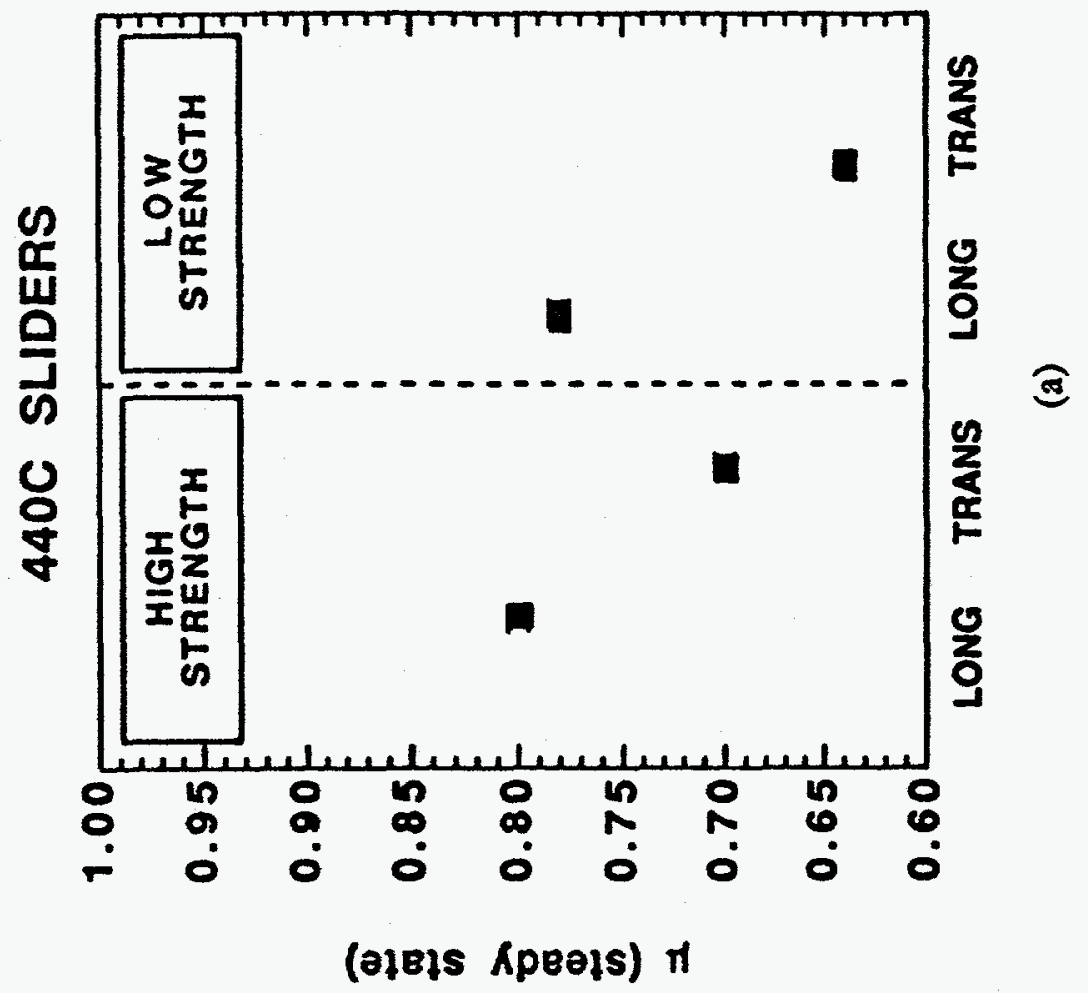




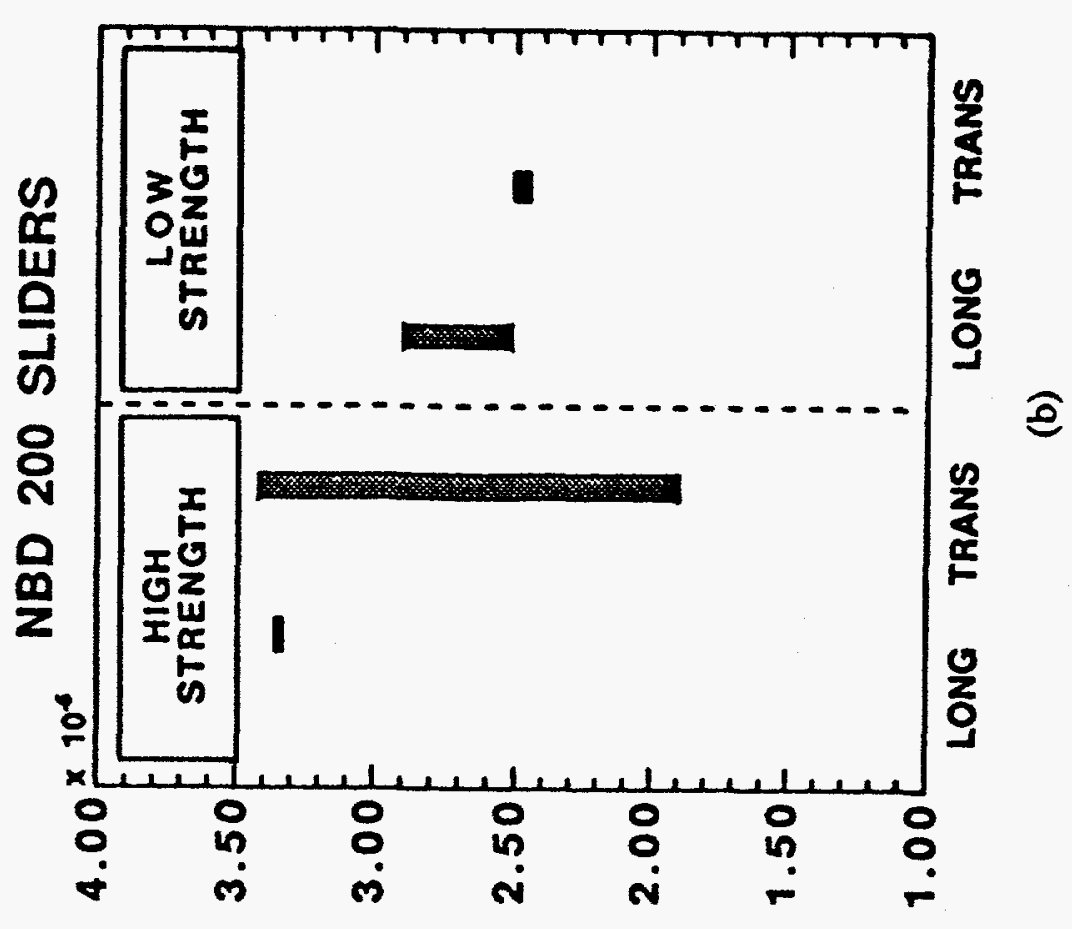

(OKO-N/EmU) $\exists L \forall Y ~ Y \forall \exists M$

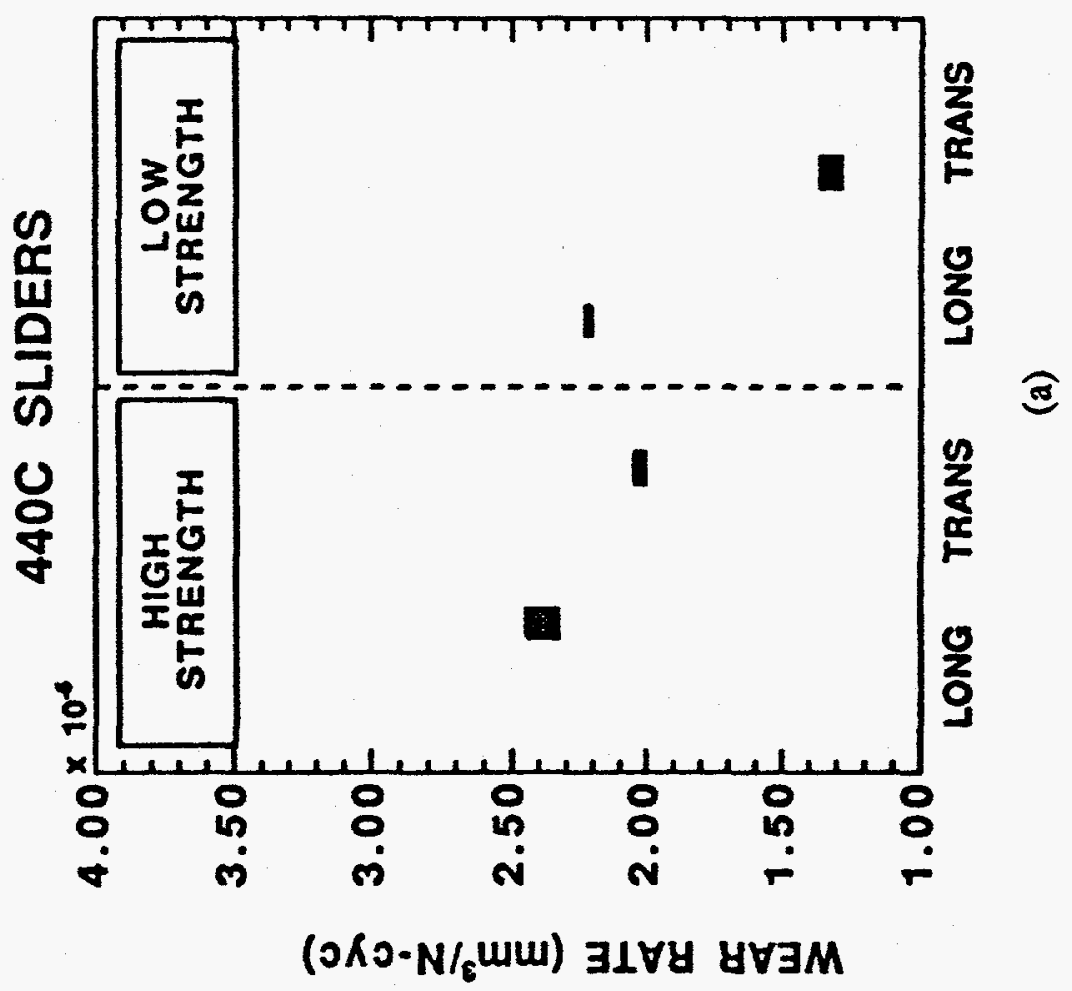




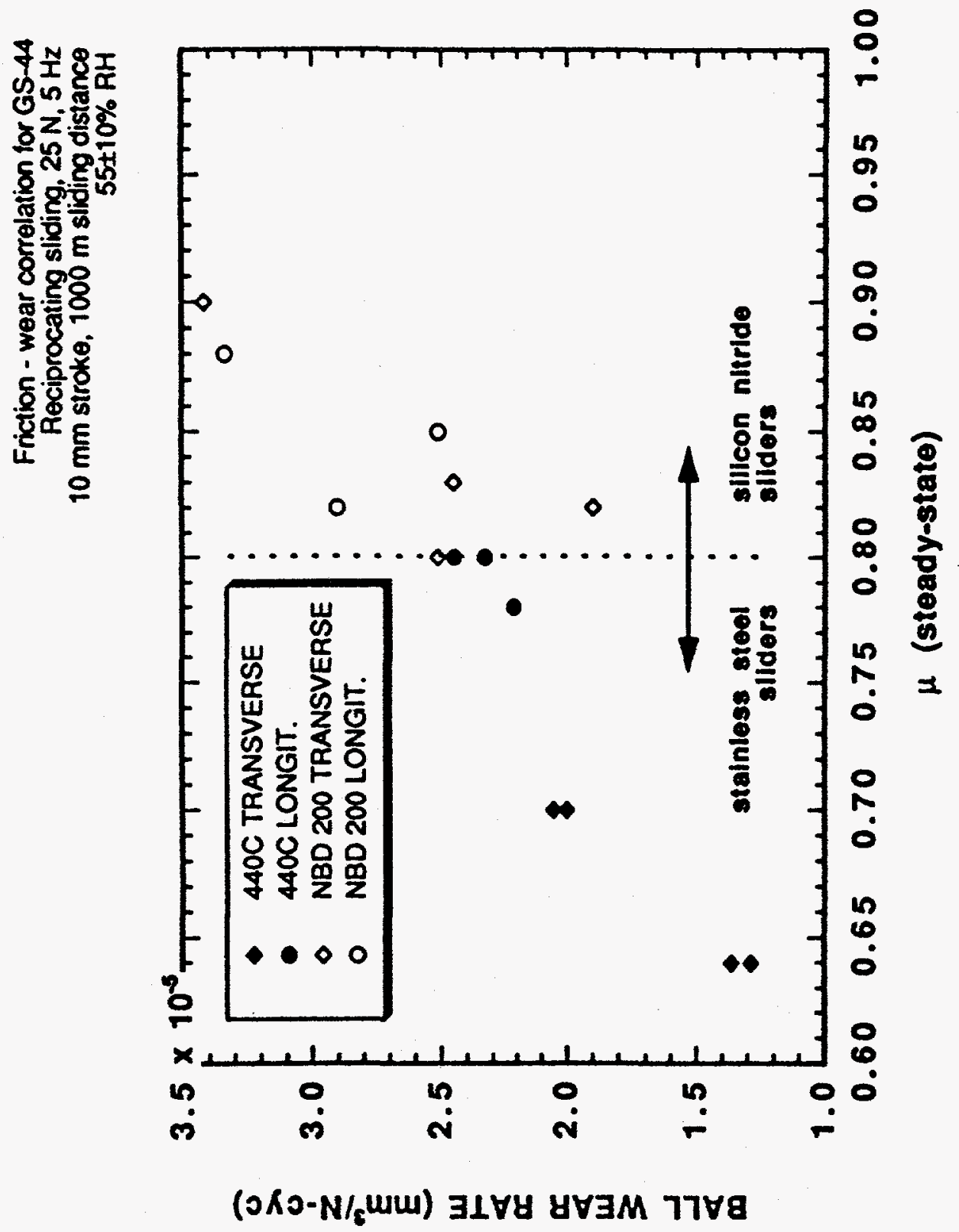




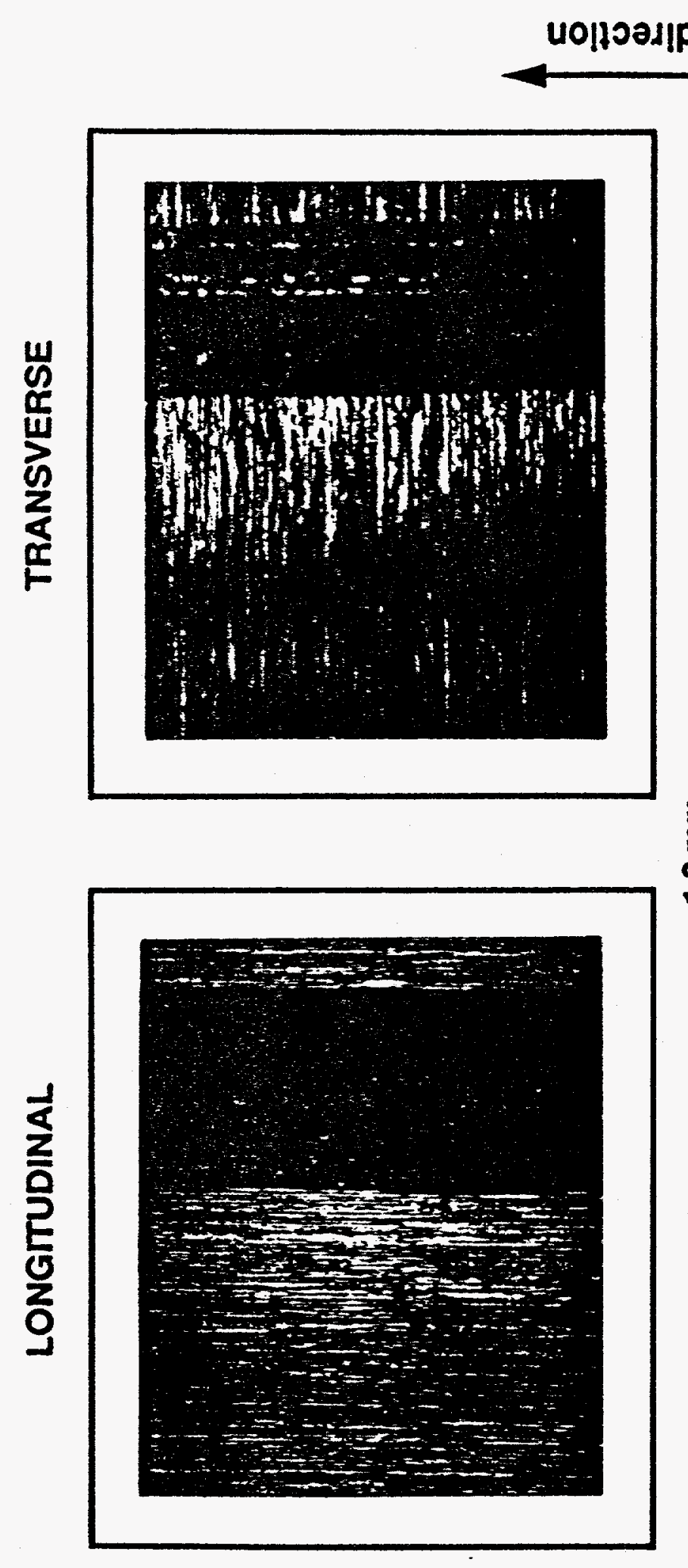

HLONJYLS HOIH

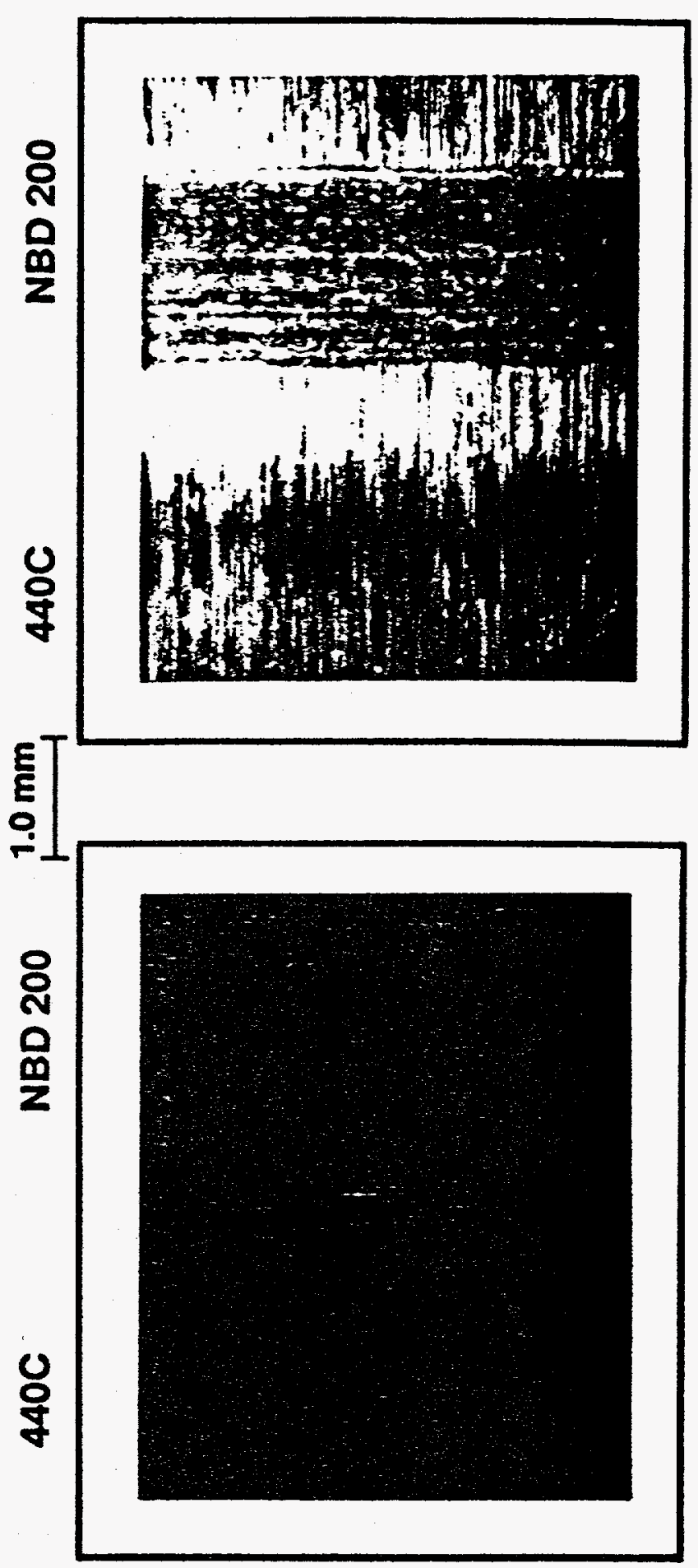

HLONGYLS MO7 


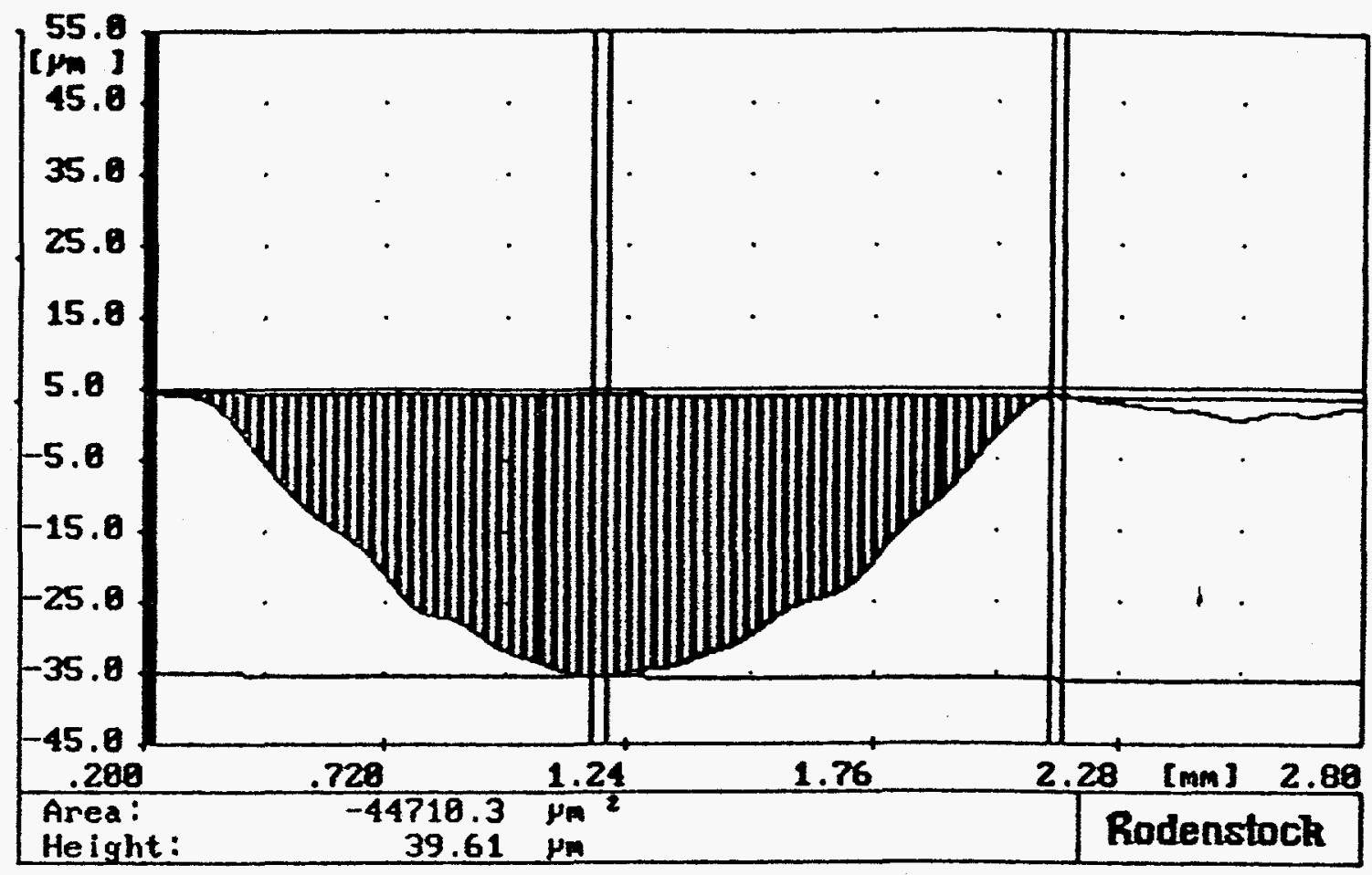

Figure 5

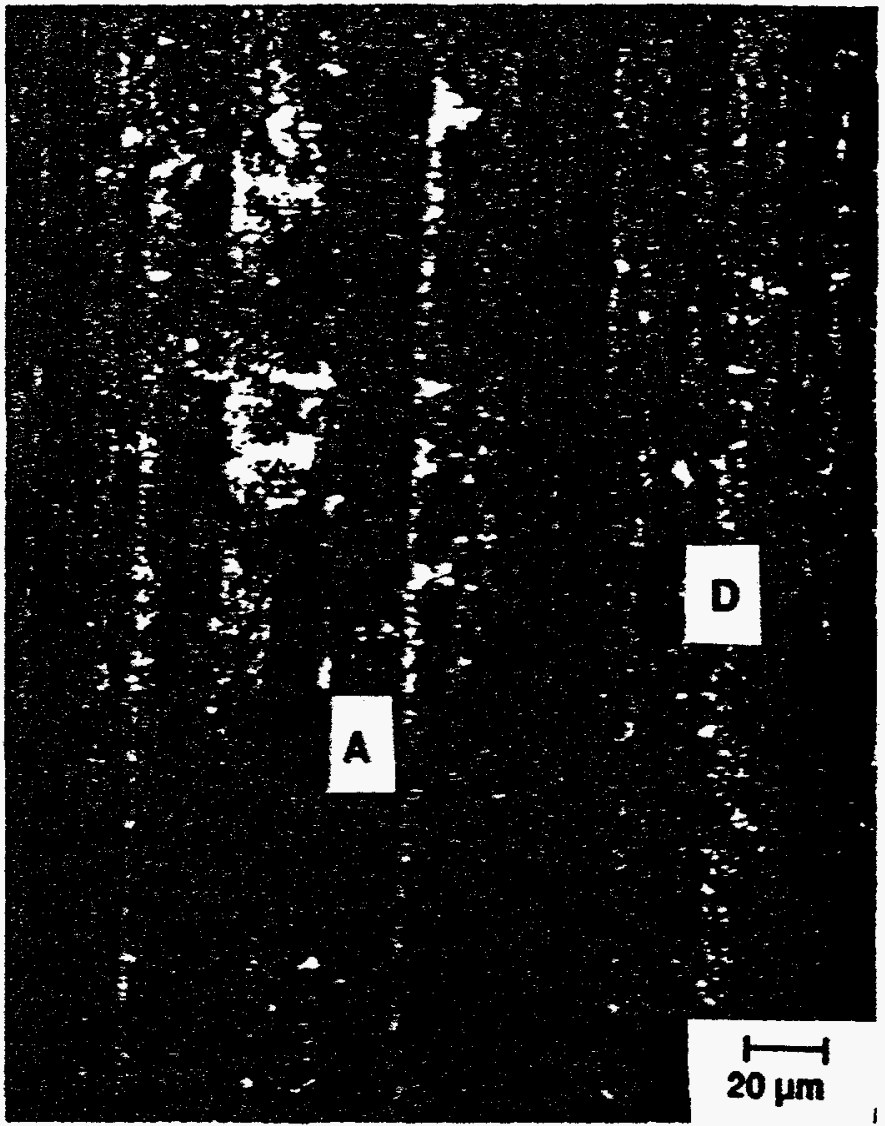

Figure 7 


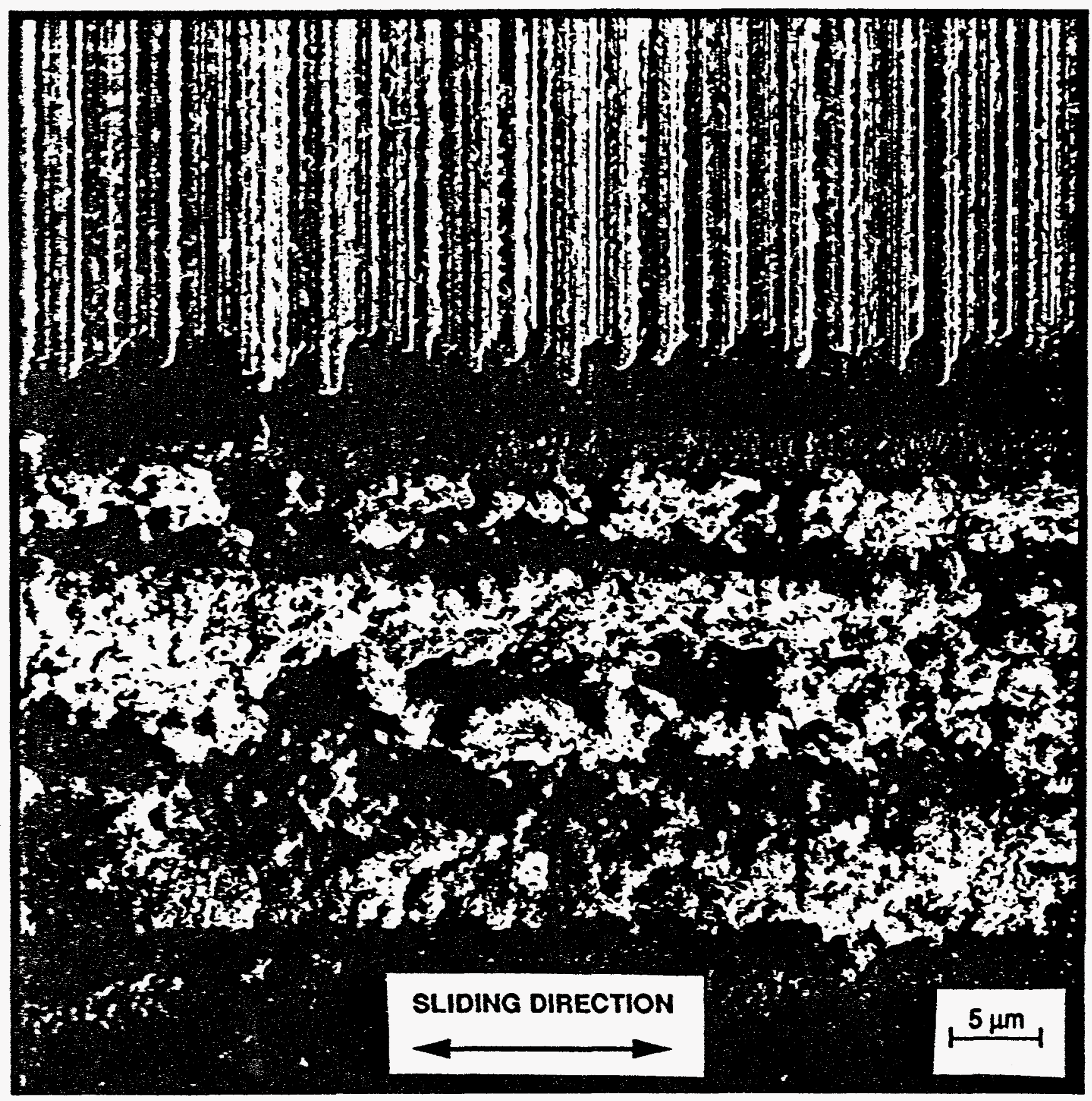

Figure 6 


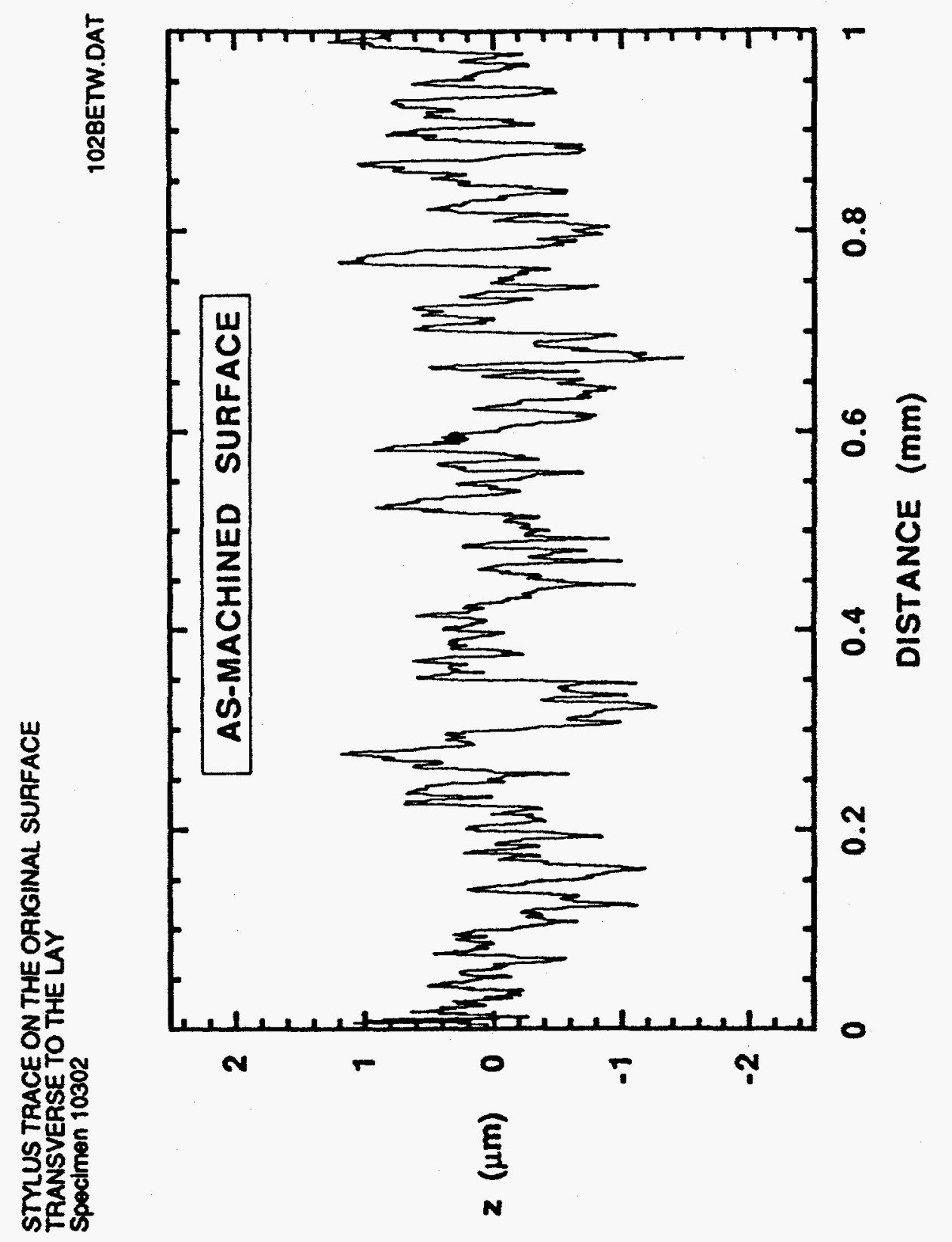




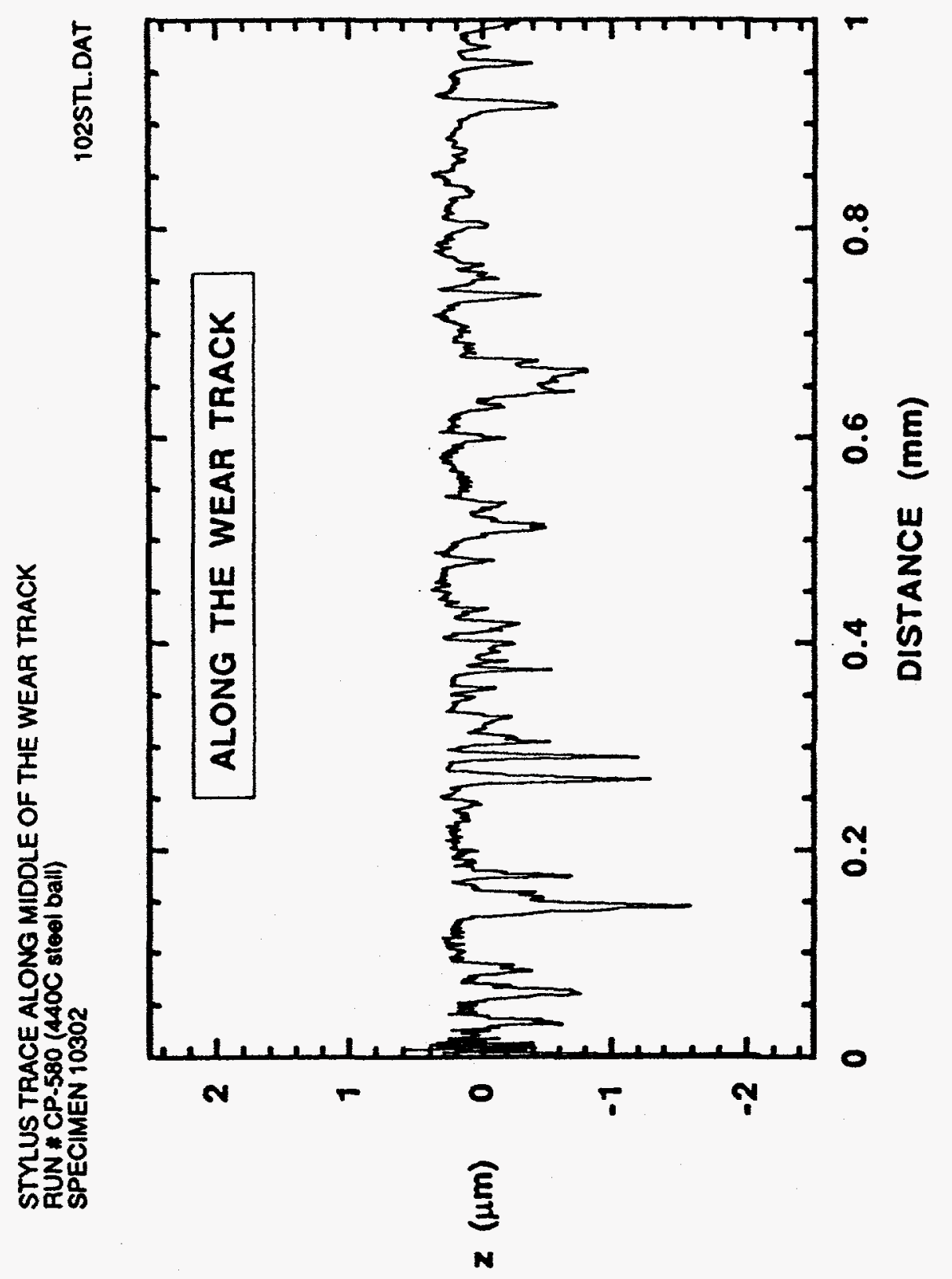




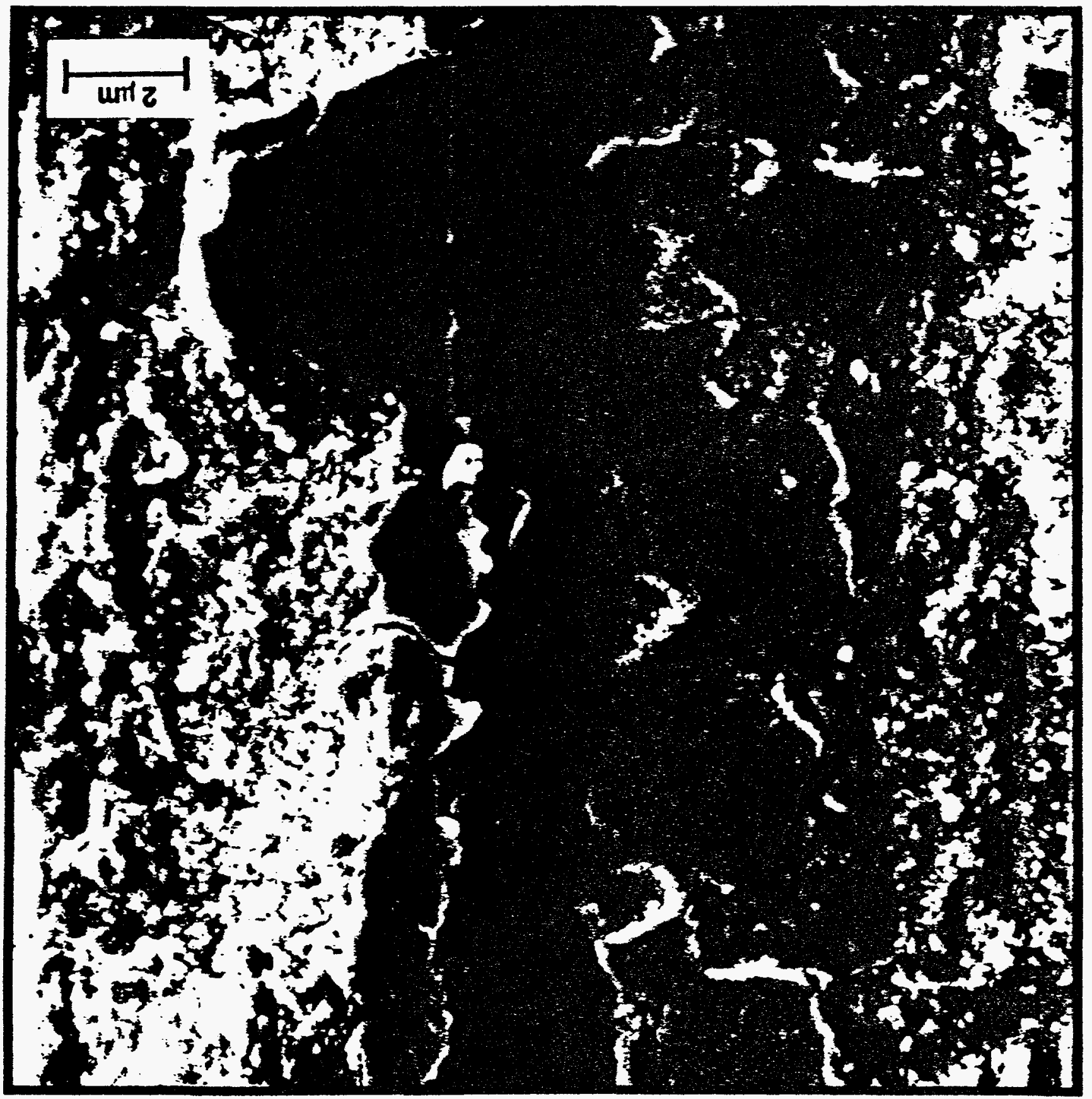



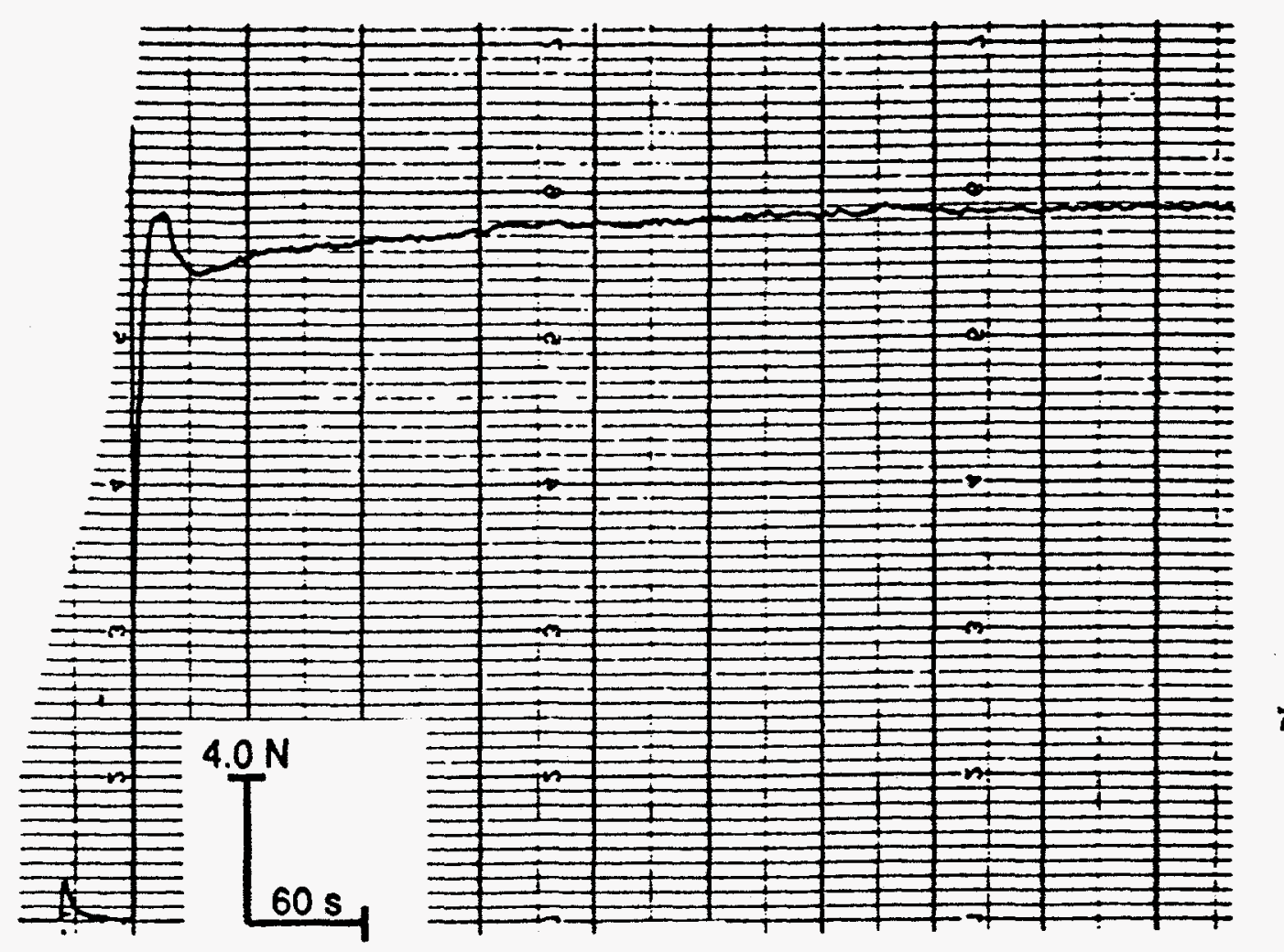

(a)

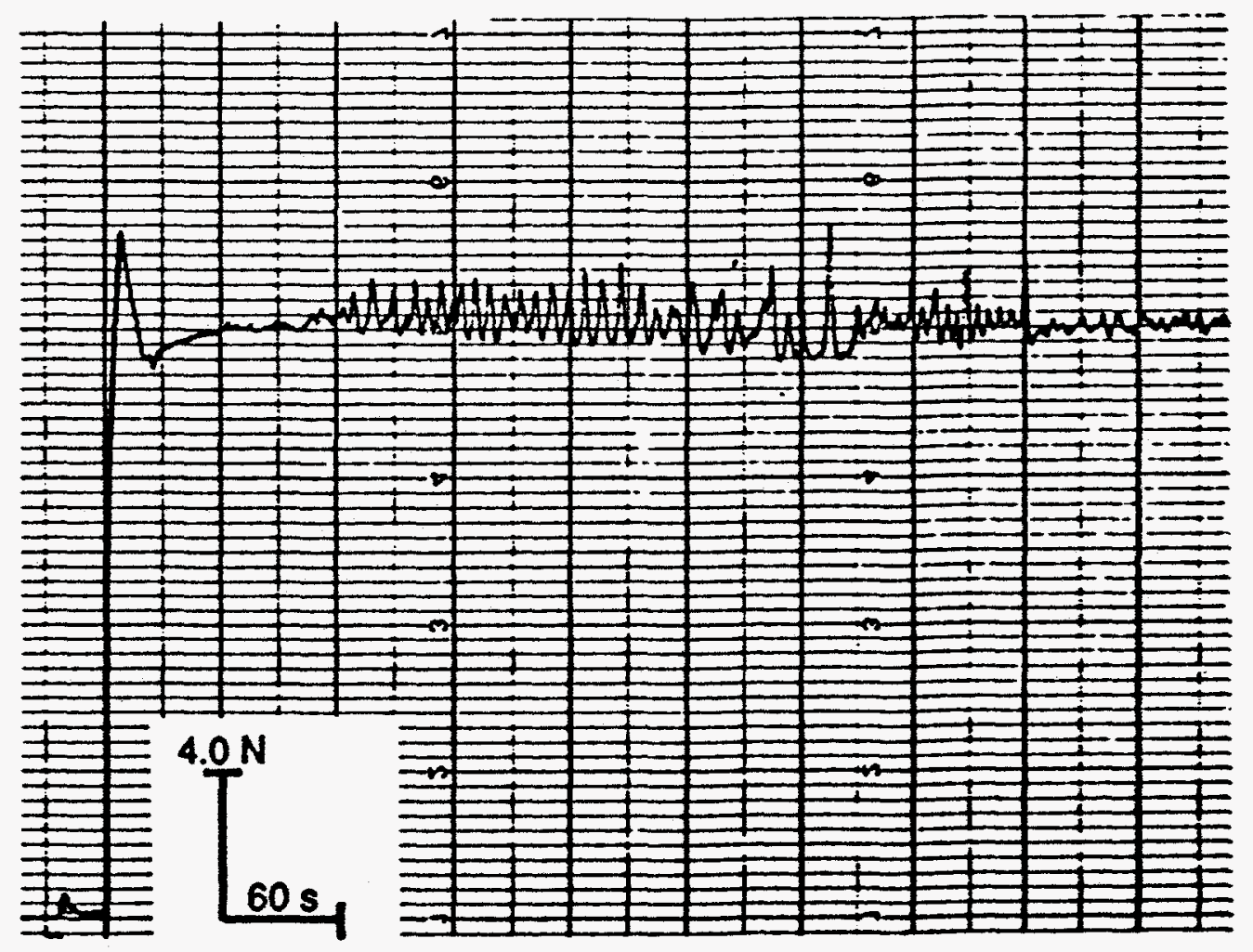

(b) 


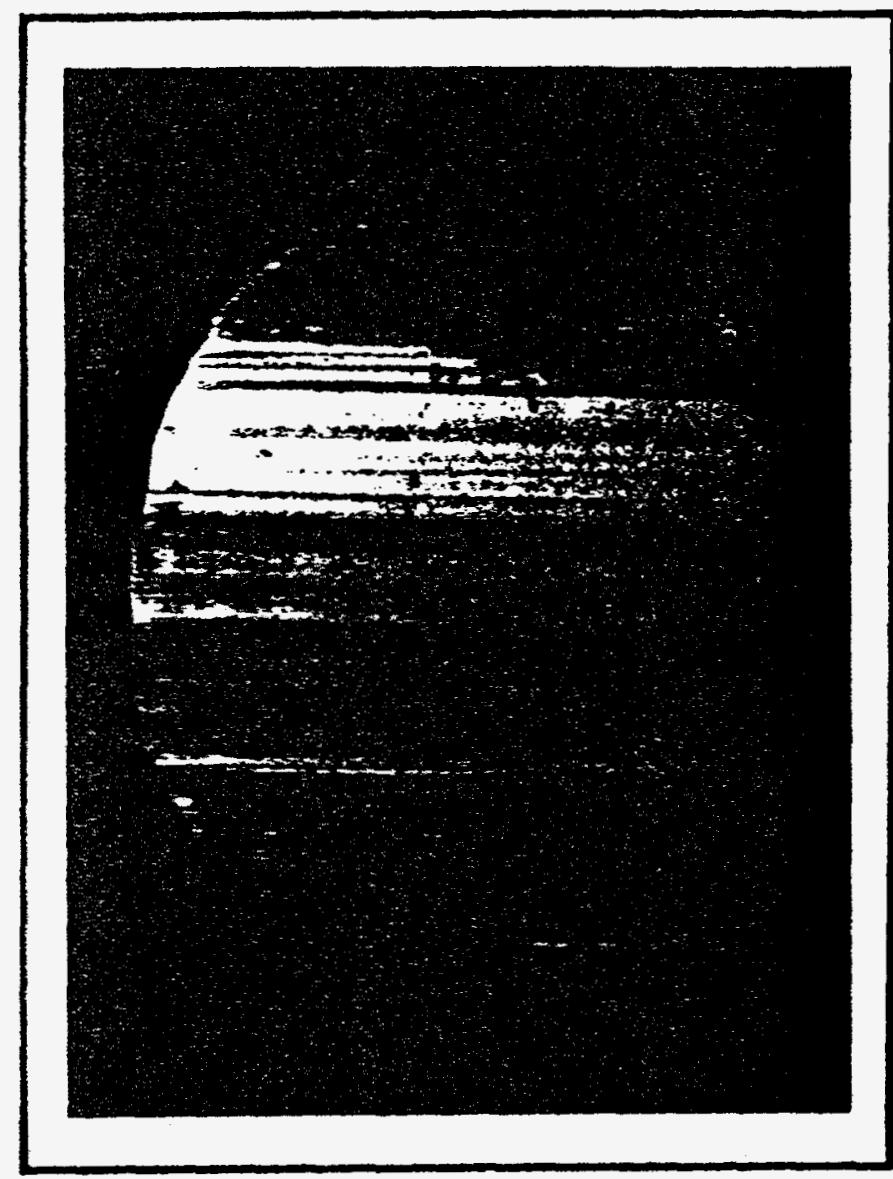

$\underset{200 \mu \mathrm{m}}{1-1}$

Figure 11 


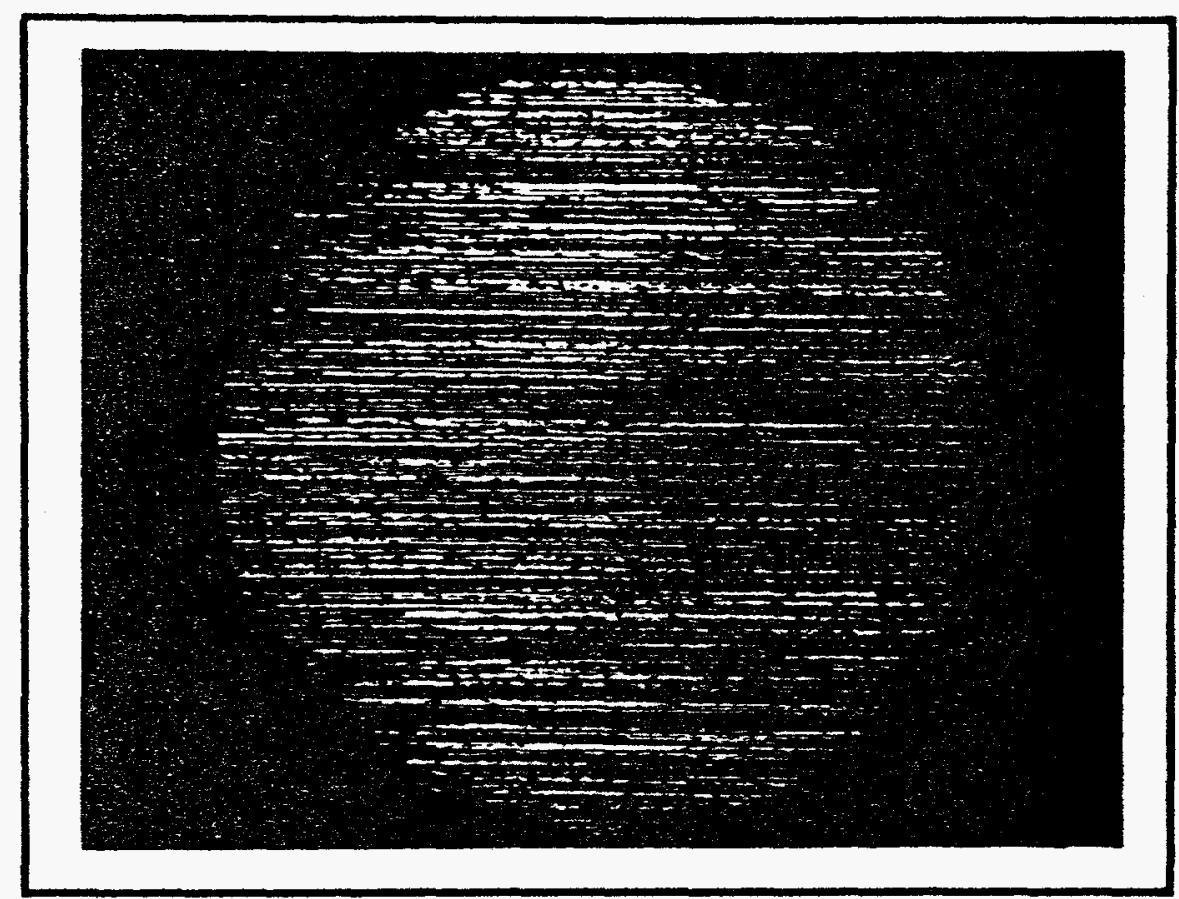

으

T章

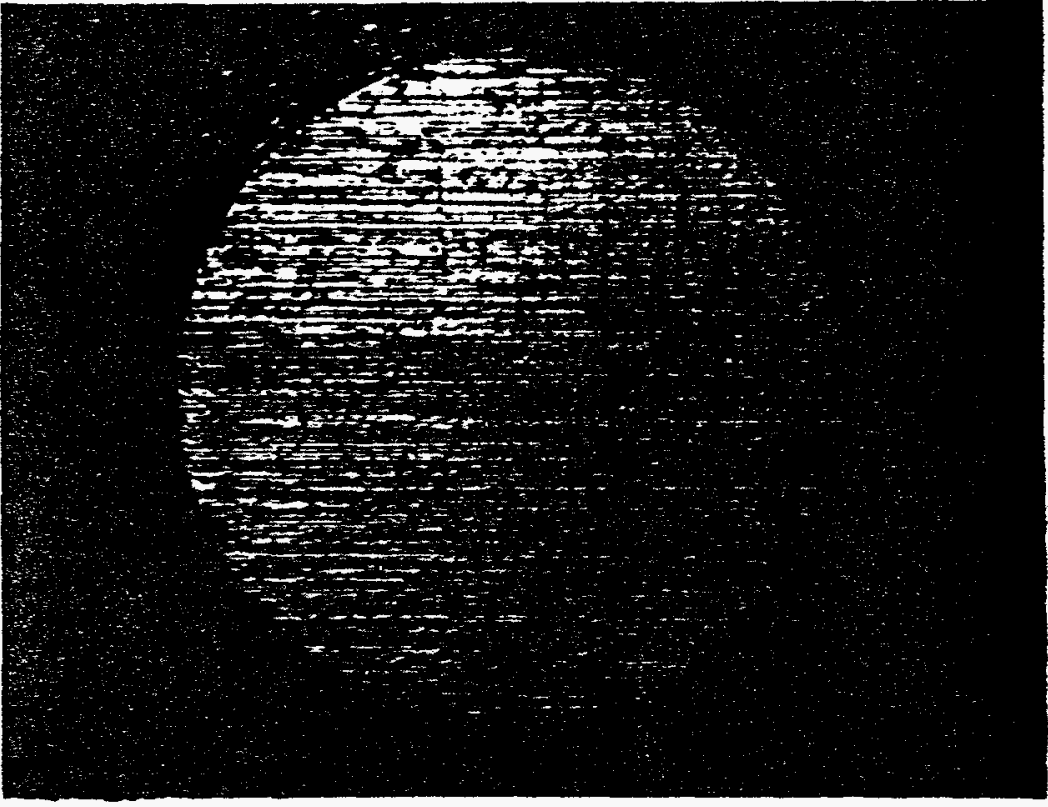

ब 